\title{
Population genetics of the Honduran spiny-tailed iguana Ctenosaura melanosterna: implications for conservation and management
}

\author{
Stesha A. Pasachnik ${ }^{1,2, *}$, Arthur C. Echternacht ${ }^{1}{ }^{\text {Benjamin M. Fitzpatrick }}{ }^{1}$ \\ ${ }^{1}$ University of Tennessee, Department of Ecology and Evolutionary Biology, Knoxville, Tennessee 37996, USA \\ ${ }^{2}$ Bay Islands Foundation, Roatan, Bay Islands, Honduras
}

\begin{abstract}
In conservation, difficult decisions concerning prioritization of different geographic areas must be made. Large-scale prioritization methods such as defining biodiversity hotspots and crisis ecoregions have paved the way; however, these efforts then need to be localized. Various approaches have been taken, such as defining evolutionarily significant units (ESUs), management units, and core habitat areas within the range of a taxonomic species. These units can then be ranked as candidates for conservation, with the goal of preserving a given species by protecting only a subset of populations. Here we used a combination of amplified fragment length polymorphisms (AFLPs) and DNA sequence data to elucidate the relationships within and among populations of the spinytailed iguana Ctenosaura melanosterna throughout its range in Honduras. Our findings indicate that there are 2 ESUs corresponding to geographically and ecologically distinct island and mainland habitats. Management strategies consisting of translocation or captive breeding and release should not consider the island and mainland populations exchangeable. In addition, the narrow geographic range of each group suggests that no region or subpopulation is likely expendable. This study demonstrates a situation, most likely increasingly common in conservation, in which it seems that only the high priority areas remain.
\end{abstract}

KEY WORDS: Evolutionarily significant unit · ESU • Conservation genetics • Prioritization · AFLPs • BayeScan · Ctenosaura melanosterna $\cdot$ STRUCTURE

\section{INTRODUCTION}

We are in the midst of an extinction crisis, in which biodiversity is being lost at a rate that greatly exceeds that of the natural rate at which species have gone extinct throughout time (e.g. Pimm et al. 1995, Myers \& Knoll 2001, Wake \& Vredenburg 2008). Habitat destruction, overexploitation, pollution, invasive species, disease, and climate change are among the top threats to biodiversity. The development and enforced protection of designated areas, and programs for captive breeding and re-introduction, are among the principal means by which conservation biologists combat this loss. In principle, and given the limited amount of funding available for such conservation initiatives, these efforts should be prioritized so as to maximize what is protected.

Large-scale methods of prioritizing areas in order to protect the greatest amount of biodiversity have been developed using the criteria of vulnerability and irreplaceability. These methods include the development of 'biodiversity hotspots' (Myers et al. 2000), 'crisis ecoregions' (Hoekstra et al. 2005), 'last of the wild' (Sanderson et al. 2002), and 'high biodiversity wilderness areas' (Mittermeier et al. 2003) (see Brooks et al. 2006 for a complete review). Controversy has been raised over these various methods of prioritization due to confusion over their criteria, resulting in target maps that overlap as little as one-tenth of each other (Brooks et al. 2006). In addition, these methods have been crit- 
icized for not incorporating clear guidance on a local scale and thus for inherent weakness when applied to the implementation of conservation actions on the ground (Mace 2000, Brummitt \& Lughadha 2003).

In practice, decisions regarding reserve establishment center around flagship or charismatic threatened species (Caro et al. 2004), and a variety of socioeconomic factors (Davis 2005, Stewart \& Possingham 2005). Even so, 2 questions should be addressed in these cases so that funds are allocated in the most effective way. First, are the individuals to be protected representative of the target species, or will a given reserve system fail to protect an irreplaceable component of the group's evolutionary diversity? Second, are the populations to be protected viable in the long term, or will efforts be wasted by setting aside marginal sites that are not likely to be self-sustaining?

To address the first question, conservation biologists have developed concepts like distinct population segments (DPSs, as defined under the US Endangered Species Act [ESA]) and evolutionarily significant units (ESUs; Ryder 1986, Waples 1991, Dizon et al. 1992, Moritz 1994, Crandall et al. 2000). Protecting such variation might be important for aesthetic or cultural reasons, but also for preserving the evolutionary processes that create diversity (Ryder 1986, Waples 1991, Crandall et al. 2000). Thus, focusing on intraspecific variation, or the preservation of multiple populations, by defining these units is a vital component to conservation and management, and is critical to the long-term persistence of a species (Hughes et al. 1997, Hobbs \& Mooney 1998, Luck et al. 2003, Avise 2005). Although there is ample evidence for this, there are still issues surrounding how to define and identify these intraspecific units (Woinarski \& Fisher 1999).

Ryder (1986) proposed that ESU status should be given to populations that represent significant adaptive variation based on concordance between data sets, such as natural history, distribution, and genetics, and that gene flow should be considered and protected. Under the ESA, protection can be granted to DPSs; however, the definition of a DPS is unclear. Waples (1991) proposed that DPSs be equivalent to ESUs, and 2 criteria were given: populations must have been reproductively isolated and must be adaptively distinct, thus representing distinct components of an 'evolutionary legacy.'

In 1994, another framework was proposed, which stated that populations must be reciprocally monophyletic for mtDNA and show significant divergence at nuclear loci in order to be given ESU status (Moritz 1994, Moritz \& Cicero 2004). This approach focuses on putatively neutral loci and thus ignores adaptive differences in favor of protecting history. Under this framework, small populations that have been greatly affected by a bottleneck, for example, might be the ones that are given ESU status. In addition, the evolutionary process will not necessarily be protected because of the explicit focus on phylogeographic history rather than local adaptation and gene flow. Similarly, groups that have gone through rapid diversification will not necessarily be given the chance to persist independently under this framework.

Crandall et al. (2000) proposed criteria for ESUs that focus on genetic and ecological exchangeability in the past and present, emphasizing a continuum of possibilities. ESU status comes from rejecting exchangeability, but there is a continuum of management recommendations depending on the combination of ecological and genetic outcomes in both a historical and recent setting. A difficulty with this concept is that ecological exchangeability is rarely testable by direct experimentation. However, this framework does focus on adaptive differences and evolutionary potential, and acknowledges the importance of gene flow in management.

A common problem in defining ESUs is that too few or too many populations receive status, which is due in part to the variety of definitions. Waples (2006) reviewed the various definitions in the context of Pacific salmon Oncorhynchus spp. (Salmonidae). He concluded that they are problematic, as his review resulted in either one or hundreds of ESUs, depending on the criteria used. Thus, he called for additional studies using empirical data. The subjectivity of the different definitions is problematic, but identifying what is likely to be lost versus maintained, and evaluating alternative management strategies must be the overall goals of conservation science.

The objective of our research was to understand the genetic structure of the spiny-tailed iguana Ctenosaura melanosterna, including potentially adaptive differences, within and among its remaining populations, which are subject to varying levels of protection. We used mtDNA and amplified fragment length polymorphism (AFLP) data to test whether populations are genetically exchangeable and evaluated whether there is evidence of recent demographic instability (which might imply problems with population viability over and above the overt anthropogenic threats; Finn et al. 2009).

\section{MATERIALS AND METHODS}

Study system. Ctenosaura melanosterna is a mediumsized spiny-tailed iguana (200 to $350 \mathrm{~mm}$ snout-vent length, SVL) that is primarily herbivorous though opportunistically carnivorous in some life stages (Köhler 2003, Gutsche 2005, McCranie et al. 2005). The species is endemic to Honduras and occurs within 
approximately $1316 \mathrm{~km}^{2}$ of arid tropical scrub forest in the Valle de Aguán (north-central mainland) and on 2 islands of the Cayos Cochinos Archipelago (Cayo Pequeño and Cayo Grande). It therefore occurs in the Central American biodiversity hotspot described by Myers et al. (2000) and in a crisis ecoregion as described by Hoekstra et al. (2005). Buckley \& Axtell (1997) described C. melanosterna on the basis of morphology and geography. The population in the Valle de Aguán was first noted in 1966 and assigned to Enyaliosaurus palearis (Echternacht 1968).

The island and mainland populations of this species are separately listed as Critically Endangered by the IUCN Red List Assessment of 2011 (S. A. Pasachnik unpubl. data) based on limited geographic range, increased habitat fragmentation and destruction, and over-harvesting of adults and eggs. Wilson \& McCranie (2004) declared Ctenosaura melanosterna one of the top 4 most ecologically vulnerable species in Honduras. This species has also been accepted for CITES Appendix II listing due to the threats posed by the international pet trade and its similarity to $C$. palearis. Considerable variation exists however, between, and in some cases within, the mainland and the island regions in terms of threats and protection.

The 2 islands of the Cayos Cochinos Archipelago are within the Cayos Cochinos Natural Marine Reserve administered by the Honduran Coral Reef Foundation (HCRF). Although both islands are technically protected, Cayo Pequeño gains additional protection through the presence of the HCRF research station. Cayo Grande has a small village and tourist resort on it and thus has increased threats due primarily to harvesting and feral dogs and cats (S. A. Pasachnik pers. obs., C. E. Montgomery pers. comm.). The populations on the mainland have little to no local protection and a higher threat level. A population of Ctenosaura melanosterna occurs within Pico Bonito National Park in the Valle de Aguán; however, this population is not afforded much protection due to a lack of policing in the area. In addition, the populations in the Valle de Aguán as a whole are threatened by large-scale habitat destruction and fragmentation, feral dogs and cats, and harvesting of adults and eggs. Harvesting is greatly increased in this area due to a festival that celebrates the consumption of this species.

Given the extreme nature of the threats to the Valle de Aguán populations, it will be difficult for Ctenosaura melanosterna to persist if the current rates of habitat destruction and consumption continue. Increasing the level of protection on the mainland will be no easy task. Thus, understanding the urgency of this action is important. Protection is already in place for the Cayos Cochinos populations (although it does vary between islands). Thus the question becomes, is the species adequately conserved if the Valle de Aguán population is allowed to go extinct and C. melanosterna persists only on the Cayos Cochinos? If iguanas in the 2 regions are genetically distinct and locally adapted, this lack of exchangeability supports the need for increased protection of the Valle de Aguán populations.

As part of an ongoing project characterizing the distribution of Ctenosaura melanosterna within the Valle de Aguán, the habitat has been surveyed for a variety of characteristics (S. A. Pasachnik unpubl. data). The dominant tree species is Acacia riparia (Leguminosae). Other abundant plants in the region include Opuntia sp., Stenocereus sp. (Cactaceae), and to a lesser extent Hematoxylum brasileto (Caesalpiniaceae), all of which are eaten by $C$. melanosterna. The average height among sites of the maximum emergent tree is $12 \mathrm{~m}$, and the average height of the canopy is $5 \mathrm{~m}$. Deforestation as well as soil and water contamination is very high in these areas due to local agricultural activity associated with cattle farming and the presence of a large Dole fruit plantation (S. A. Pasachnik unpubl. data; for photos, see Fig. 1, and Fig. S1 in the supplement at www.int-res.com/articles/suppl/n014p113.pdf).

Bermingham et al. (1998) conducted a survey of Cayos Cochinos Pequeño over a $4 \mathrm{~d}$ visit in 1995. During this time, a preliminary inventory of the flora and a characterization of the different vegetation types were conducted. The dominant vegetation type found was evergreen oak forest, which was estimated to cover approximately $50 \%$ of the island and be made up of at least $90 \%$ Quercus cf. oleoides (Fagaceae). The understory in these forests is made up of Calliandra (Fabaceae-Mimosoideae), Connarus (Connaraceae), Alibertia edulis (Rubiaceae), Cupania (Sapindaceae), and Ouratea (Ochnaceae) (Bermingham et al. 1998). Most of the oak trees are slow growing and several hundred years old, ranging from 5 to $10 \mathrm{~m}$ in the windier areas of the island to $35 \mathrm{~m}$ tall along some of the ridges. Most have hollow tree trunks, which are optimal retreat sites for iguanas. Mature mixed forests also occur to some degree on the island, where few oak trees are found and the canopy consists mostly of evergreens ranging from 30 to $35 \mathrm{~m}$ tall. Palms are scattered throughout the island and on the 3 main beaches. Button mangrove Conocarpus erectus (Combretaceae) and mangrove fern Acrostichum aureum (Adiantaceae) can also be found in a small marsh area on the island (Bermingham et al. 1998; see the supplement to the present paper for general habitat photos). Although this survey was only conducted on Cayos Cochinos Pequeño, the islands are ecologically extremely similar (Wilson \& Cruz Diaz 1993; S. A. Pasachnik pers. obs., C. E. Montgomery pers. comm.).

There is little to no overlap in the vegetation of these 2 geographic isolates of Ctenosaura melanosterna. 
Cayos Cochinos is dominated by evergreen oak forest, whereas Acacia and cacti dominate the Valle de Aguán. Given that there is little to no overlap in vegetation, it is clear that individuals from each population have different diets. Likewise there are expected differences in reproductive biology, as the different habitats afford different soil types and occur in areas of highly different weather patterns (S. A. Pasachnik pers. obs.); thus the egg deposition, clutch size, and timing of reproduction most likely vary (Colli 1991, Gillis \& Ballinger 1991, Iverson et al. 1993, Jenkins et al. 2009). In addition to ecological differences, the geography of the area clearly shows that the mainland and island populations are not only separated by an expanse of land but also by the Caribbean Sea (separating the islands from the mainland 8000 to 9000 years ago; see Toscano \& Macintyre 2003 for sea level curves). Thus, current gene flow between these areas is extremely unlikely.

Field collection. DNA samples were collected from individuals across the geographic range of Ctenosaura melanosterna within the Valle de Aguán and Cayos Cochinos in Honduras over a 5 yr period from 2004 to 2009 (Fig. 1). The exact locations of these individuals are not recorded herein, as the 2 geographic isolates of this species are Critically Endangered and listed under CITES Appendix II due to the threats they face from the international pet trade. Additional information concerning this topic may be requested from the authors.

Upon capture, a digital photograph was taken and SVL, tail length, sex, and weight were recorded. In addition, each individual was given a unique mark, with bead tags and paint, to avoid re-sampling. Either a $1 \mathrm{~cm}$ section of the tail tip was removed and stored in $100 \%$ ethanol, or a $0.5 \mathrm{ml}$ sample of blood was drawn from the caudal vein and stored in an EDTA buffer (Longmire et al. 1992) for molecular analysis. Different sampling techniques were used depending on when the sample was collected; earlier samples were taken from the tail tip as blood-drawing techniques were perfected. For individuals from which a tissue sample was taken, the area was disinfected with ethanol prior to removal, and pressure was applied to the wound until bleeding ceased, and the area was sealed with a topical skin adhesive to prevent infection. For individuals from which a blood sample was taken, the area around the puncture site was disinfected with ethanol before the blood was drawn and was sealed with a topical adhesive after blood had been drawn.
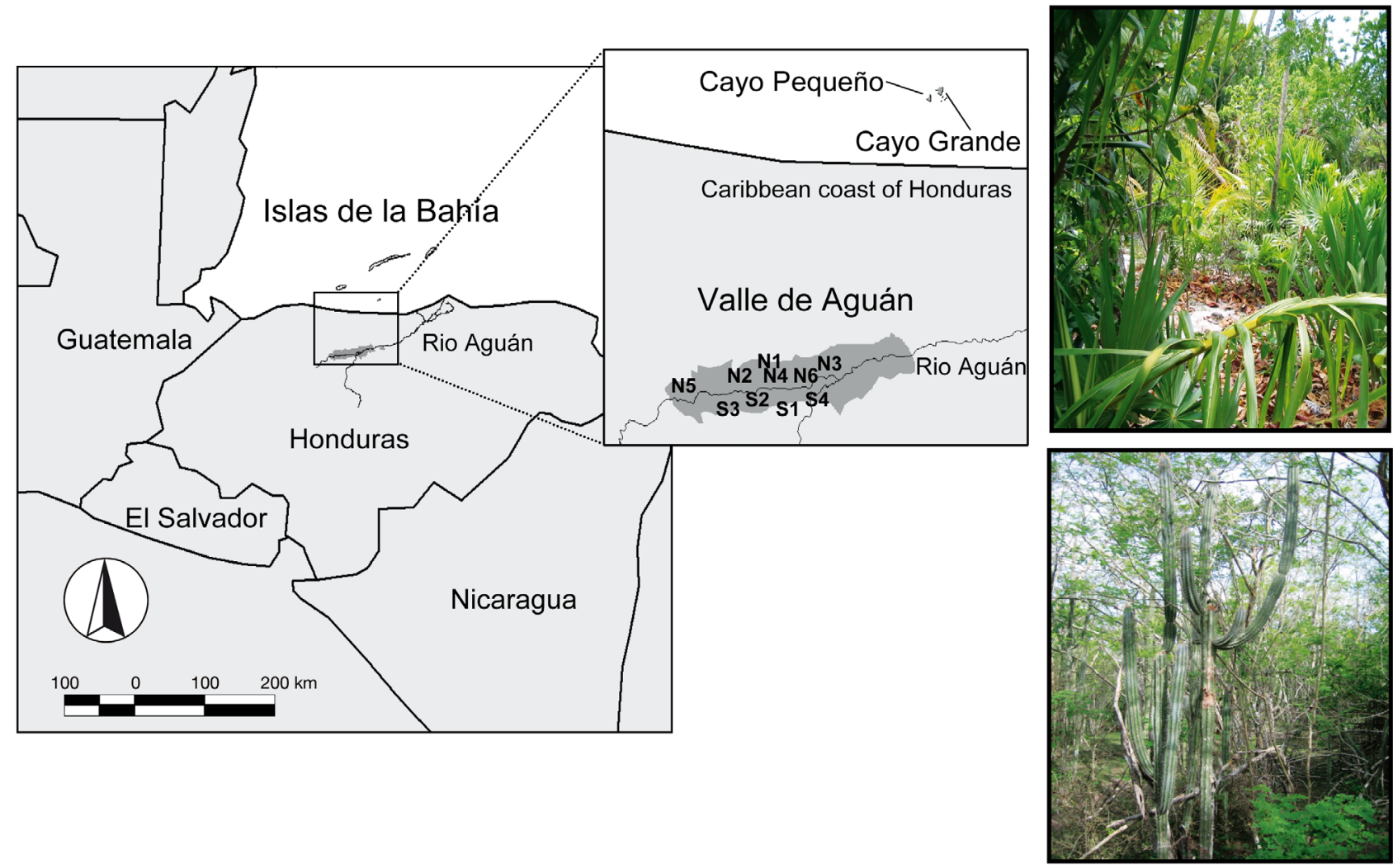

Fig. 1. Ctenosaura melanosterna. Distribution of the Honduran spiny-tailed iguana in the Valle de Aguán and Cayos Cochinos (Pequeño Grande), Honduras. Top photo: typical beach habitat of Cayos Cochinos including numerous palms (credit: C.E. Montgomery). Bottom photo: typical habitat in the Valle de Aguán with a cactus in the foreground (credit: J. Corneil) 
DNA sequencing. Genomic DNA was extracted using the Qiagen DNeasy extraction kit. The polymerase chain reaction (PCR) was used to amplify portions of 2 mitochondrial markers, $674 \mathrm{bp}$ of NADH dehydrogenase subunit 4 and $1067 \mathrm{bp}$ of cytochrome oxidase B (CytB). For primer sequences and PCR procedures, see Pasachnik et al. (2009). PCR products were verified by gel electrophoresis, and successful amplicons were purified using exonuclease I/shrimp alkaline phosphatase (ExoSAP). Sequencing reactions were performed using the PCR primers and were aligned using Sequencher 4.6 (Gene Code Corporation). Ambiguous base calls were verified manually by examining the forward and reverse electropherogram reads. Sequences were aligned with published Ctenosaura and sequences from GenBank (e.g. accession numbers AF217774, U66227, EU246733, AF020252, AF020254) using MacClade 4.07 (Maddison \& Maddison 2005). We assayed 81 individuals for the 2 mitochondrial markers. C. palearis was used as the outgroup. All sequences were submitted to Genbank and deposited under GenBank accession numbers GU331986GU331993, GU332005-GU332012, and GU906223.

Mitochondrial DNA analysis. The $2 \mathrm{mtDNA}$ loci were combined to estimate a mitochondrial genealogy using a Bayesian and maximum likelihood (ML) approach. Bayesian posterior probabilities were estimated using MrBayes 3.1 (Ronquist \& Huelsenbeck 2003) with 4 Markov chains, the temperature profile at the default setting of 0.2 , run for 2 million generations, and sampling every 100th generation with a final burn-in of 10000 generations. ML analysis was conducted in PAUP* 4.0 (Swofford 2002) using a heuristic search with 1000 random-taxon-addition replicates. Confidence at each node was assessed using nonparametric bootstrapping (Felsenstein 1985) based on 1000 pseudo-replicates with 10 random-taxon-addition replicates per pseudo-replicate. The optimal model of sequence evolution for each locus was determined in Modeltest 3.7 (Posada \& Crandall 1998). We used SplitsTree 4.10 to estimate unrooted networks using parsimony, neighbor-joining, and minimum spanning networks. All yielded the same topology, which was congruent with the ML gene tree.

Using the program Arlequin version 3.11 (Excoffier et al. 2005) we tested various hypotheses of genetic structuring by running analyses of molecular variance (AMOVAs) based on a priori groupings created by considering geographic barriers. The first grouping tested considered the 2 island populations together, the north side of the Rio Aguán, and the south side of the Rio Aguán as 3 separate groups. The second tested the islands individually as well as the north and south side of the river, giving 4 different groups. We then used the program SAMOVA version 1.0 (spatial analy- sis of molecular variation, Dupanloup et al. 2002) to explore the population structuring without the use of any a priori groups. This method assigns sampling sites or populations to groups based on geographic proximity and genetic homogeneity through a simulated annealing procedure. The number of groups must be specified for each run. Since we sampled 12 locations we assessed each number of groups $(K)$ ranging from 2 to 11 with 100 simulated annealing simulations. By exploring different numbers of groups, the most likely groups could be determined based on the resulting $F$ statistics (Dupanloup et al. 2002), which are calculated using an AMOVA approach (Excoffier et al. 1992). Once these groups were chosen, we used the same groupings in Arlequin to estimate $p$ values relative to 10000 randomizations.

Demographic statistics. To evaluate the possibility that populations have recently experienced large demographic changes, we followed Finn et al. (2009) in testing the mtDNA data for deviations from mutationdrift equilibrium using standard test statistics in DnaSP (Rozas et al. 2003). We used the results from SAMOVA, AMOVA, and a priori groups based on geography to determine how to define populations. Since there was some variation in these results, we report on the Cayos Cochinos islands together and separately, and the Aguán Valley populations together and then grouped by the north and south sides of the Rio Aguán.

The demographic statistics used include: mean absolute error (MAE), raggedness, Fu's $F_{\mathrm{S}}$, Tajima's $D^{*}, \mathrm{Fu}$ and Li's $D$, and the growth statistic (R2) of Ramos-Onsins and Rozas (Finn et al. 2009). MAE reflects the differences between the observed mismatch distribution and the theoretical mismatch distributions under demographic expansion (for example, following a severe bottleneck). Thus MAE decreases as the probability of expansion increases (Rogers et al. 1996). Raggedness describes the smoothness of the observed pairwise difference distribution and is expected to decrease with expansion, which increases smoothness (Harpending 1994). Fu's (1997) $F_{\mathrm{S}}$ compares observed and expected haplotype frequencies (using the Ewens 1972 model, which assumes migration drift equilibrium and neutral mutation). Negative values, indicating a low probability of the observed population having as many haplotypes as the Ewens simulation, are expected with population expansion. Tajima's $D$ compares the number of segregating sites and nucleotide diversity to test the hypothesis that all mutations are neutral. Values are negative under population expansion. Fu \& Li's (1993) $D^{*}$ is similar to Tajima's $D$ but computes the number of singletons in the external branches and is expected to be negative with population expansion. The R2 statistic of RamosOnsins \& Rozas (2002) also accounts for singletons and 
has higher values with population expansion. This R2 statistic is more powerful for small populations, whereas Fu's $F_{\mathrm{S}}$ is most powerful when the population is large. For all demographic statistics, except MAE, pvalues were estimated using 1000 coalescent replicate simulations, where the observed number of segregating sites was held constant and no recombination was allowed. In addition, p-values for Tajima's $D$ and Fu and Li's $D^{*}$ were generated from the original test of the data.

We then categorized each group using these 6 demographic statistics. The possible categories of demographic stability ranged from 1 to $5 ; 1$ represents a monomorphic group inferred to be resultant of a recent founder effect or extreme bottleneck, 2 represents a recent strong bottleneck inferred from all statistics being significantly high, 3 represents a historic bottleneck inferred from some statistics being significantly high, 4 represents a long-term demographic stability inferred from no significant result, and 5 represents a long-term growth signature inferred from some statistics being significantly low (Finn et al. 2009).

While deviations from mutation-drift equilibrium might indicate demographic instability (and therefore, lower conservation value), they might also be caused by natural selection or population structure, and these alternatives cannot be distinguished when only a single marker is tested (Misawa \& Tajima 1997, Tajima 1997). In addition, category 4 ('long-term stability') is based on failure to reject a null hypothesis and is therefore inherently weak.

Nuclear data analysis. AFLP markers were obtained following the general procedure described by Vos et al. (1995), using 4 different selective primers (Fitzpatrick et al. 2008). The presence or absence of fragments was determined by running fluorescently labeled PCR product in an ABI 3100 sequencer at the University of Tennessee's sequencing facility. Peaks were aligned and called in both Genescan ${ }^{\circledR}$ Analysis Software (Applied Biosystems) and Peak Scanner ${ }^{\mathrm{TM}}$ Software v1.0 (Applied Biosystems), and then verified through visual inspection of each chromatogram. A complete technical replicate, from restriction-ligation through selective PCR, was performed for each individual by multiplexing with 2 different colored primers. Only those sites and individuals that showed the same pattern with both color primers were used in this analysis.

To evaluate population structure without a priori assumptions of groups, we used the clustering Markov chain Monte Carlo (MCMC) algorithm in STRUCTURE 2.2 (Pritchard et al. 2000, Falush et al. 2007). To infer the number of genetic clusters $(K)$ best supported by the data, we used both the approximate posterior probabilities (Pritchard et al. 2000), and delta $K$ method
(Evanno et al. 2005). For each $K$ from 1 to 8, we ran the MCMC 10 independent times with 10000 burn-in generations and 100000 sampling generations. Due to inconsistency in missing data between primers, the data from each primer were evaluated separately. All individuals with any missing data were then removed and the analysis was repeated, such that 51 individuals were included. Lastly, we removed the loci that were thought to be affected by selection, as discussed below, and repeated the analysis.

To directly address the question of island-mainland differentiation, we estimated multi-locus $F_{\mathrm{ST}}$ (proportion of genetic variation between populations and groups overall) using the program AFLP-SURV 1.0 (Vekemans 2002) and screened for individual outlier markers using BayeScan (Foll \& Gaggiotti 2008). BayeScan uses posterior probability estimates to evaluate hierarchical models in which individual loci or populations are allowed to contribute differentially to the overall $F_{\mathrm{ST}}$. AFLP markers linked to loci contributing to differential local adaptation between island and mainland habitats are expected to show greater than average $F_{\mathrm{ST}}$ if there is ongoing gene flow or if isolation is recent (such that mutation and drift have not yet maximized $F_{\mathrm{ST}}$ for most markers). Because we were concerned with rigorously evaluating the possibility of local adaptation rather than identifying or counting candidate loci, we used a high threshold $\left(\operatorname{Pr}\left\{\alpha_{i} \neq 0\right.\right.$ । data $\left.\}>0.99\right)$, where $\alpha$ is the locus-specific contribution to the global $F_{\mathrm{ST}}$, for accepting evidence of divergent selection. This is expected to produce a high false negative rate for AFLPs if the underlying model is correct (Foll \& Gaggiotti 2008). However, unrecognized population structure (Excoffier et al. 2009) or deviations from the assumed mutation process for AFLPs might increase the false positive rate. No estimate of false positive rate for a situation such as the one described herein exists (Foll \& Gaggiotti 2008); however, the number of candidate loci in the most extreme bin (posterior probability $>0.99$ ) is greater than the number with posterior probability between 0.95 and 0.99 . This is not expected if only false positives are being identified.

\section{RESULTS}

\section{Mitochondrial DNA analysis}

The results from the gene tree analysis, AMOVA, and SAMOVA all show support for genetic structure separating the island populations from the mainland populations, a separation between the populations on the north and south side of the Rio Aguán, and a possible separation between the 2 island populations. This indicates that the island populations have been pre- 
sent for longer than predicted if they were established by recent human introductions, over the last $100 \mathrm{yr}$ or so. The mitochondrial gene tree reveals that there were no haplotypes shared between the mainland and Cayo Cochinos samples. In the Cayos Cochinos, 1 common haplotype is shared between the 2 islands, 2 are unique to the Cayo Pequeño sample, and 1 is unique to the Cayo Grande sample. On the mainland, 2 haplotypes are found only on the north side of the river, and 3 haplotypes on both the north and south sides of the river. The south side of the river had no unique haplotypes in this sample; however, 1 haplotype was found only on the south side of the river and in an area on the north side, close to the narrowing of the river (Figs. $1 \& 2$ ).

The SAMOVA analysis showed that as the number of groups increased the $F_{\mathrm{CT}}$ (the proportion of variation among groups) increased (see Fig. S2a in the supplement at www.int-res.com/articles/suppl/n014p113_ supp.pdf) whereas $F_{\mathrm{SC}}$ (the proportion of genetic variation between populations within groups) decreased (Fig. S2b), as predicted by Dupanloup et al. (2002). A plateau in the $F_{\mathrm{CT}}$ values exists from $K=3$ through $K=$ 10 , which suggests that dividing the populations into additional groups does not substantially improve the predicted population structure. We did see an increase a

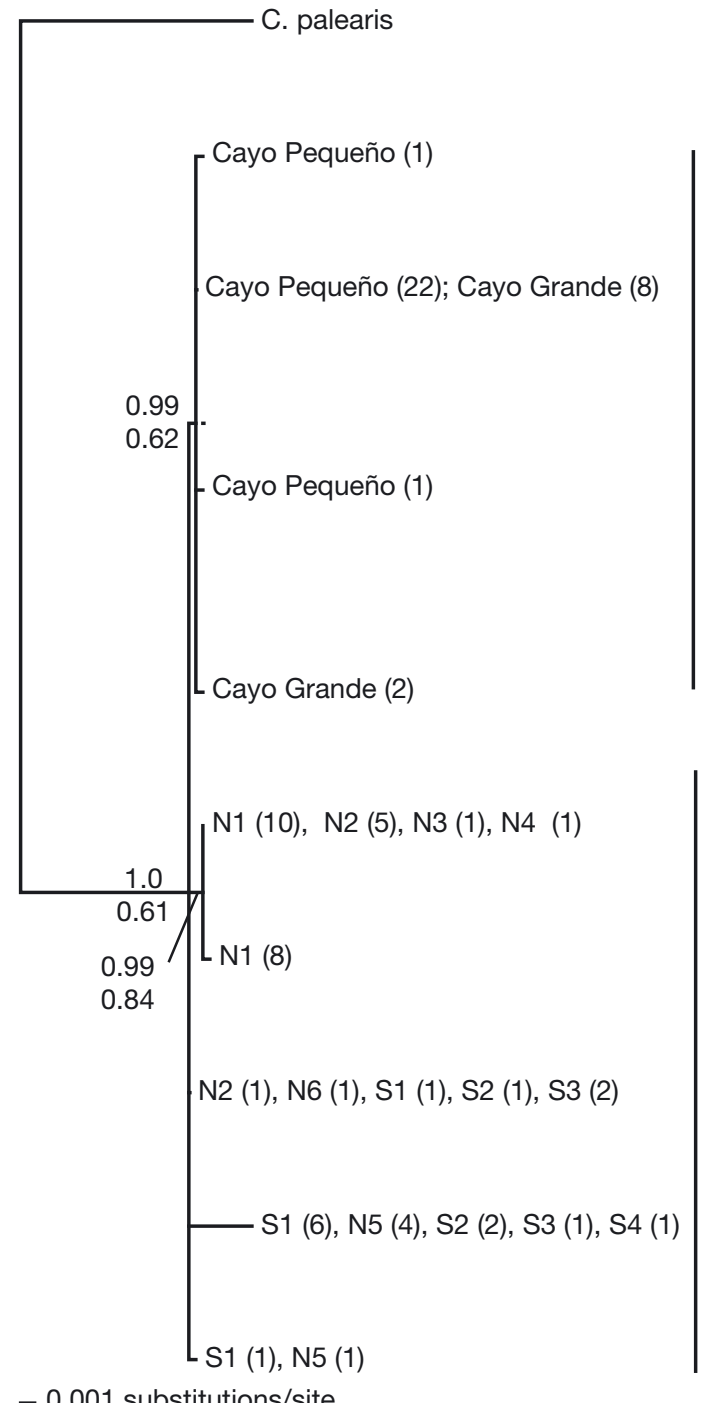

b

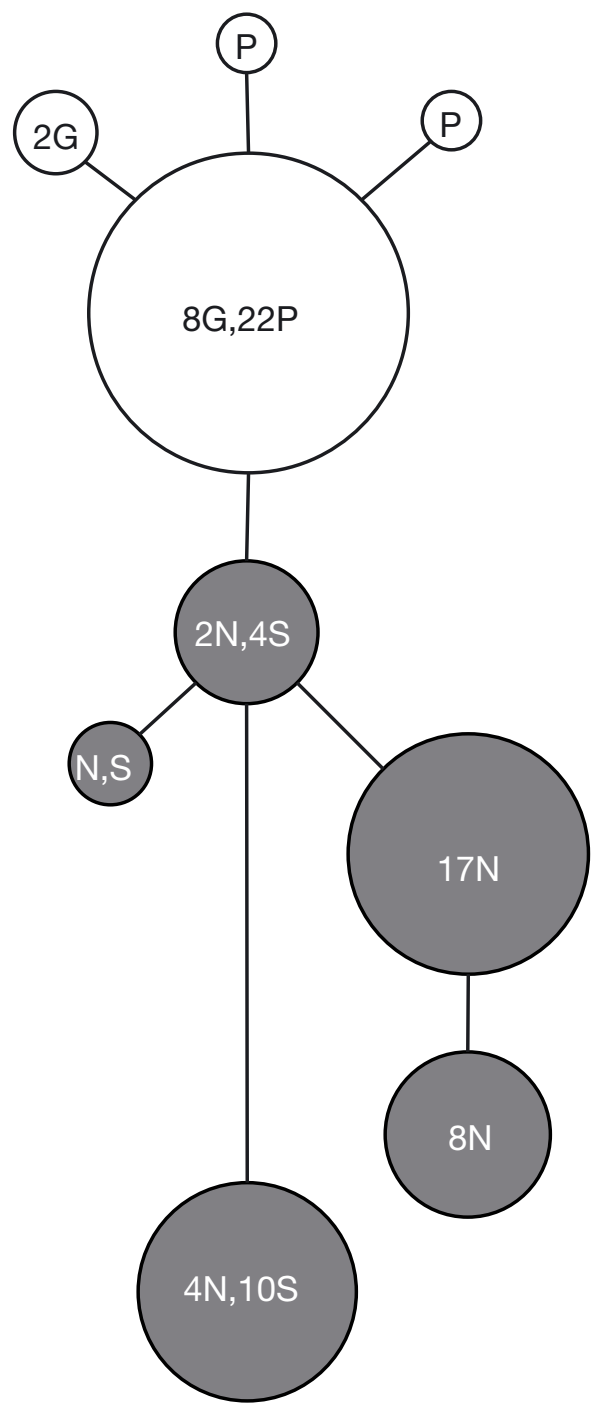

Fig. 2. (a) Maximum likelihood and Bayesian combined mitochondrial gene tree. Values above nodes represent posterior probabilities, and values below nodes represent bootstrap support. Values inside parentheses indicate sample size. S: south of the Rio Aguán and N: north of the Rio Aguán. (b) Haplotype network. Circles represent observed haplotypes, and their areas are directly proportional to the number of individuals in the sample with that haplotype. Branches are proportional to the number of basepair differences between haplotypes. Within each circle are the numbers of individuals from Cayos Cochinos Grande

(G) and Pequeño (P) or from North $(\mathrm{N})$ and South $(\mathrm{S})$ of the Rio Aguán on the mainland (see Fig. 1 for locations) 
in $F_{\mathrm{CT}}$ after $K=10$, but this is likely an artifact of having only 1 individual sampled for some sites (Fig. S2). When 3 groups were specified, the Cayos Cochinos islands grouped together, and there was a split mostly corresponding to the north and south sides of the river on the mainland (Table 1). Given this structure, $75 \%$ of the variation is explained as differences among

Table 1. A priori and spatial analysis of molecular variation (SAMOVA) groupings for 3 and 4 groups. Percent variation and associated significance obtained from AMOVA for both sets of groups. Numbers of individuals are given in parentheses

\begin{tabular}{|c|c|c|}
\hline & A priori & SAMOVA \\
\hline \multicolumn{3}{|l|}{ Three groups } \\
\hline \multirow[t]{6}{*}{ North of Rio Aguán } & N1 & N1 (18) \\
\hline & N2 & N2 (6) \\
\hline & N3 & N3 (1) \\
\hline & N4 & N4 (1) \\
\hline & N5 & N6 (1) \\
\hline & N6 & $\mathrm{S} 4$ (1) \\
\hline \multirow[t]{4}{*}{ South of Rio Aguán } & $\mathrm{S} 1$ & $\mathrm{~S} 1(8)$ \\
\hline & $\mathrm{S} 2$ & $\mathrm{~S} 2(3)$ \\
\hline & $\mathrm{S} 3$ & S3 (3) \\
\hline & $\mathrm{S} 4$ & N5 (5) \\
\hline \multirow[t]{2}{*}{ Cayos Cochinos } & Cayo Grande & Cayo Grande (10) \\
\hline & Cayo Pequeño & Cayo Pequeño (24) \\
\hline \multirow{2}{*}{$\begin{array}{l}\text { Among group } \\
\text { p-value }\end{array}$} & 40.97 & 75.26 \\
\hline & $0.05 \pm 0.01$ & $0.00 \pm 0.00$ \\
\hline \multirow{2}{*}{$\begin{array}{l}\text { Among populations } \\
\text { within groups } \\
\text { p-value }\end{array}$} & 34.73 & 2.2 \\
\hline & $0.00 \pm 0.00$ & $0.05 \pm 0.01$ \\
\hline \multirow{2}{*}{$\begin{array}{l}\text { Within populations } \\
\text { p-value }\end{array}$} & 24.3 & 22.54 \\
\hline & $0.00 \pm 0.00$ & $0.00 \pm 0.00$ \\
\hline \multicolumn{3}{|l|}{ Four groups } \\
\hline \multirow[t]{6}{*}{ North of Rio Aguán } & N1 & N1 (18) \\
\hline & N2 & N2 (6) \\
\hline & N3 & N3 (1) \\
\hline & N4 & N4 (1) \\
\hline & N5 & \\
\hline & N6 & \\
\hline \multirow[t]{4}{*}{ South of Rio Aguán } & S1 & S1 (8) \\
\hline & $\mathrm{S} 2$ & $\mathrm{~S} 2(3)$ \\
\hline & S3 & N5 (5) \\
\hline & $\mathrm{S} 4$ & \\
\hline \multirow{2}{*}{$\begin{array}{l}\text { Cayos Cochinos } \\
\text { Grande }\end{array}$} & Cayo Grande & Cayo Grande (10) \\
\hline & & $\begin{array}{c}\text { Cayo Pequeño (22) } \\
\text { N6 (1) }\end{array}$ \\
\hline \multirow{2}{*}{$\begin{array}{l}\text { Cayos Cochinos } \\
\text { Pequeño }\end{array}$} & Cayo Pequeño & S3 (3) \\
\hline & & $\mathrm{S} 2(1)$ \\
\hline \multirow{2}{*}{$\begin{array}{l}\text { Among group } \\
\text { p-value }\end{array}$} & 17.99 & 76.19 \\
\hline & $0.20 \pm 0.02$ & $0.00 \pm 0.00$ \\
\hline \multirow{2}{*}{$\begin{array}{l}\text { Among populations } \\
\text { within groups } \\
\text { p-value }\end{array}$} & 55.85 & 0.84 \\
\hline & $0.001 \pm 0.001$ & $0.61 \pm 0.016$ \\
\hline \multirow{2}{*}{$\begin{array}{l}\text { Within populations } \\
\text { p-value }\end{array}$} & 26.16 & 22.97 \\
\hline & $0.00 \pm 0.00$ & $0.00 \pm 0.00$ \\
\hline
\end{tabular}

groups, and these results were significantly different from random grouping $(p=0.00 \pm 0.00)$. When 4 groups are specified, we still see the islands together; however, there are basically 2 groups south of the Rio Aguán and 1 group north of the Rio Aguán (Table 1). Given this structure, $76 \%$ of the variation is among groups, only a $1 \%$ 'improvement' over $K=3$.

The AMOVA results based on a priori grouping consistent with geography largely agree with the 3 group structuring from the SAMOVA results. The only difference is that 1 site on the north side of the river grouped with the south side, and 1 group from the south side grouped with the north side in the SAMOVA $K=3$ model. The AMOVA analysis indicated that $41 \%$ of the variation was among groups, and this result was significant under the $K=3$ model where the islands were grouped together and the north and the south side of the river were separate $(p=0.05 \pm 0.01)$. However, when the 2 islands were separated for the $K=4$ model, we found that only $18 \%$ of the variation was among groups, and this result was not significantly better than random grouping (Table 1). This configuration has 13860 unique permutations, so there would have been ample power to reject the null hypothesis if it was the grouping that maximized $F_{\mathrm{CT}}$ given $K=4$ (Fitzpatrick 2009).

\section{Demographic statistics}

The null hypothesis of mutation-drift equilibrium was not rejected when the 4 populations inferred from the mtDNA were used (Table 2). Thus, following Finn et al. (2009), we are unable to reject the null hypothesis of long-term demographic stability.

\section{Nuclear data analysis}

Using the clustering methods, approximate posterior probabilities, and delta $K$, in STRUCTURE 2.2, we found that variation in the best number of groups is exhibited between the 4 primers (Fig. S3 in the supplement at www.int-res.com/articles/suppl/n014p113_ supp.pdf). Two primers indicated the greatest support for $K=2,1$ primer for $K=1$, and 1 for $K=3$ (Fig. S3). This indicates substantial heterogeneity among markers in the degree of differentiation. However, when the data from all primers were run together, for the subset of 51 individuals, we saw support for $K=2$. In addition, all primers exhibited statistically significant multilocus differentiation between a priori groupings according to the randomization test in AFLP-SURV (Table 3). Our analysis using STRUCTURE might be conservative in identifying clusters, but the putative clusters found correspond well with expectations based on geogra- 
Table 2. Ctenosaura melanosterna. Sample size (n), population genetic information, and demographic statistics for each population. Significance $\left(^{*}\right)$ is based on $\mathrm{p}<0.05$ and was calculated for all data using the data and coalescent simulations (following Finn et al. 2009). Demographic statistics include mean absolute error (MAE), raggedness (rg), Fu's $F_{\mathrm{S}}$, Tajima's $D$, Fu and Li's $D^{*}$, and the growth statistic of Ramos-Onsins and Rozas (R2) (see 'Materials and methods' for details)

\begin{tabular}{|c|c|c|c|c|c|c|}
\hline & Cayos Cochinos & Cayo Pequeño & Cayo Grande & Aguán Valley & North of Rio & South of Rio \\
\hline $\mathrm{n}$ & 34 & 24 & 10 & 47 & 31 & 16 \\
\hline No. of haplotypes & 4 & 3 & 2 & 5 & 5 & 3 \\
\hline Nucleotide diversity & 0.00014 & 0.00010 & 0.00021 & 0.00306 & 0.00160 & 0.00249 \\
\hline \multicolumn{7}{|l|}{ Demographic statistics } \\
\hline MAE & 0.12230 & 0.07390 & 0.18650 & 0.66750 & 0.64570 & 1.31220 \\
\hline rg & 0.35940 & 0.48330 & 0.20990 & 0.08980 & 0.07430 & 0.44520 \\
\hline R2 & 0.08070 & 0.13820 & 0.17780 & 0.20140 & 0.10350 & 0.20770 \\
\hline $\mathrm{D}$ & -1.55550 & -1.51469 & 0.01499 & $2.36041^{*, b}$ & -0.52703 & 1.53004 \\
\hline$D^{*}$ & -1.53788 & -2.15908 & 0.80424 & $1.51030^{*, \mathrm{~b}}$ & 1.05234 & 0.97526 \\
\hline$F_{\mathrm{S}}$ & $-2.9160^{*, \mathrm{a}}$ & -2.07800 & 0.41700 & 7.65600 & 2.49600 & 5.90600 \\
\hline Demographic category & $4 / 5$ & 4 & 4 & $3 / 4$ & 4 & 4 \\
\hline
\end{tabular}

Table 3. Multilocus $F_{\mathrm{ST}}$ values by primer from the program AFLP-SURV. CG: Cayo Grande; CP: Cayo Pequeño; N: north, and S: south of Rio Aguán. ${ }^{*} \mathrm{p}<0.0001,{ }^{* *} \mathrm{p}=0.02$

\begin{tabular}{|c|c|c|c|c|c|}
\hline \multirow[t]{2}{*}{ Primer } & \multirow{2}{*}{$\overline{\mathrm{CG}}$} & \multicolumn{2}{|c|}{ Multilocus _ } & \multirow{2}{*}{ Global } & \multirow{2}{*}{$\begin{array}{l}\text { Mainland- } \\
\text { island }\end{array}$} \\
\hline & & $\mathrm{CP}$ & $\mathrm{N}$ & & \\
\hline \multicolumn{6}{|l|}{ CTAC } \\
\hline CG & & & & $0.072^{*}$ & $0.107^{*}$ \\
\hline $\mathrm{CP}$ & 0.074 & & & & \\
\hline $\mathrm{N}$ & 0.086 & 0.103 & & & \\
\hline $\mathrm{S}$ & 0.076 & 0.103 & 0.000 & & \\
\hline \multicolumn{6}{|l|}{ CTAG } \\
\hline $\mathrm{CG}$ & & & & $0.106^{*}$ & $0.078^{*}$ \\
\hline $\mathrm{CP}$ & 0.148 & & & & \\
\hline $\mathrm{N}$ & 0.140 & 0.994 & & & \\
\hline $\mathrm{S}$ & 0.125 & 0.102 & 0.016 & & \\
\hline \multicolumn{6}{|l|}{ СТTC } \\
\hline CG & & & & $0.070^{*}$ & $0.092^{*}$ \\
\hline $\mathrm{CP}$ & 0.085 & & & & \\
\hline $\mathrm{N}$ & 0.063 & 0.101 & & & \\
\hline $\mathrm{S}$ & 0.088 & 0.092 & 0.000 & & \\
\hline \multicolumn{6}{|l|}{ CTTG } \\
\hline CG & & & & $0.013^{* *}$ & $0.039^{*}$ \\
\hline $\mathrm{CP}$ & 0.000 & & & & \\
\hline $\mathrm{N}$ & 0.010 & 0.039 & & & \\
\hline S & 0.000 & 0.036 & 0.005 & & \\
\hline
\end{tabular}

phy and mtDNA. When 3 groups were supported, the $<$ mainland and each island population were separate (Fig. 3a). When 2 groups were supported, a split was evident between Cayos Cochinos and the mainland populations (Fig. 3b,c).

Using AFLP-SURV 1.0 (Vekemans 2002), we estimated multi-locus $F_{\mathrm{ST}}$ in order to address differentiation between various populations, specifically to answer the question of mainland-island differentiation. All 4 primers showed significant $F_{\mathrm{ST}}$ values at both the global and mainland-island levels (Table 3). Although some variation in the value of $F_{\mathrm{ST}}$ does exist between primers, these values are generally low. This indicates that recent isolation is most likely the force behind this division, as contemporary gene flow between the mainland and island populations is extremely unlikely. When considering the 2 Cayos populations and the 2 mainland populations as 4 separate groups, the $F_{\mathrm{ST}}$ values differed between populations and between primers; however, $F_{\mathrm{ST}}$ was always greatest between the population north of the Rio Aguán and the Cayo Pequeño population and lowest between the 2 mainland populations (with the exception of primer CTTG), and at times between the island populations (Table 3).

BayeScan (Foll \& Gaggiotti 2008) was used to screen for individual markers with deviant levels of geographic differentiation. From the posterior probability estimates, we detected 8 AFLP bands using a threshold of $\left(\operatorname{Pr}\left\{\alpha_{i} \neq 0 \mid\right.\right.$ data $\left.\}>0.95\right)$ that show $F_{\mathrm{ST}}$ values higher than expected if due only to random variation among markers. However, because we were concerned with rigorously evaluating the possibility of local adaptation rather than identifying or counting candidate loci, we used a higher threshold $\left(\operatorname{Pr}\left\{\alpha_{i} \neq 0 \mid\right.\right.$ data $\left.\}>0.99\right)$ and detected 5 individual loci that showed evidence of exceptional divergence between the mainland and island populations (Fig. 4). These AFLP markers might be linked to loci contributing to differential local adaptation between island and mainland habitats.

Candidate markers were not evenly distributed among the 4 AFLP primers, explaining the low level of multilocus differentiation exhibited by 1 primer. This heterogeneity among primers is not unexpected, based on the heterogeneity among AFLP bands. Of 310 scored bands, $50 \%$ were fixed in the entire sample or showed only 1 in- 
CTAC

a

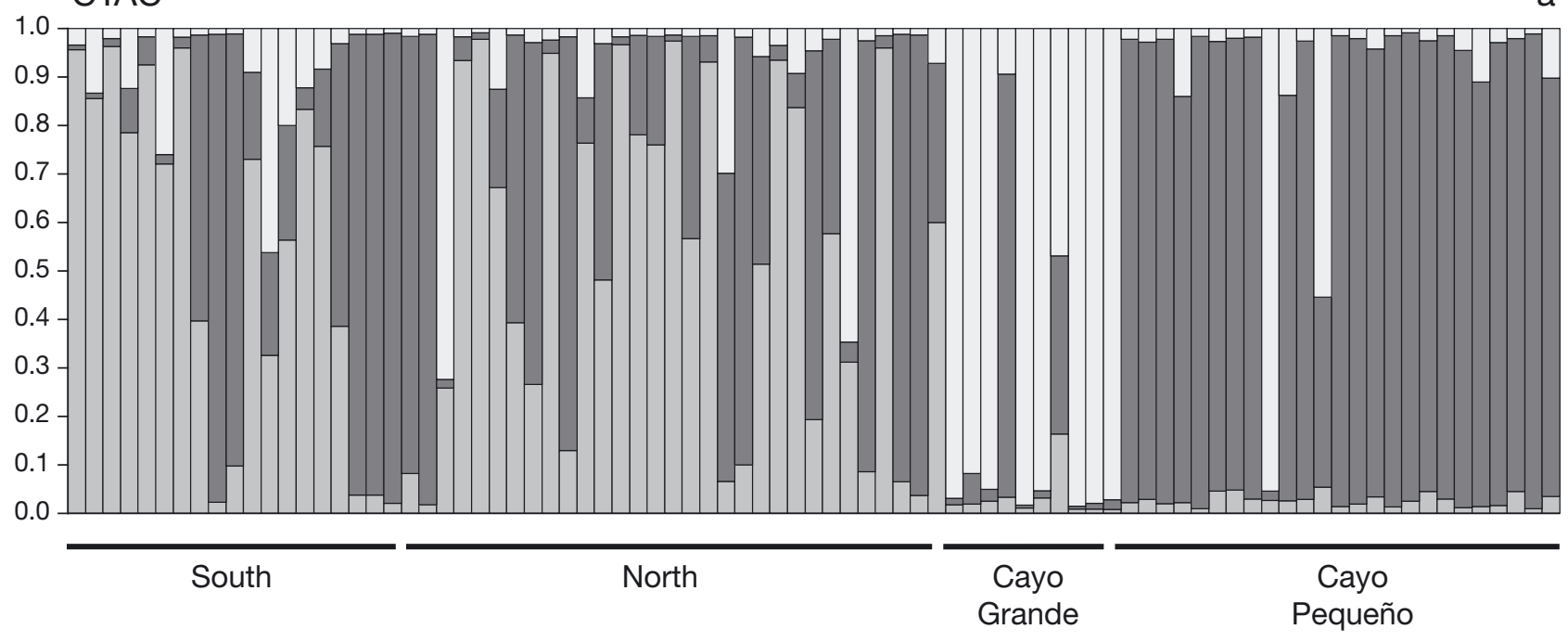

CTTC

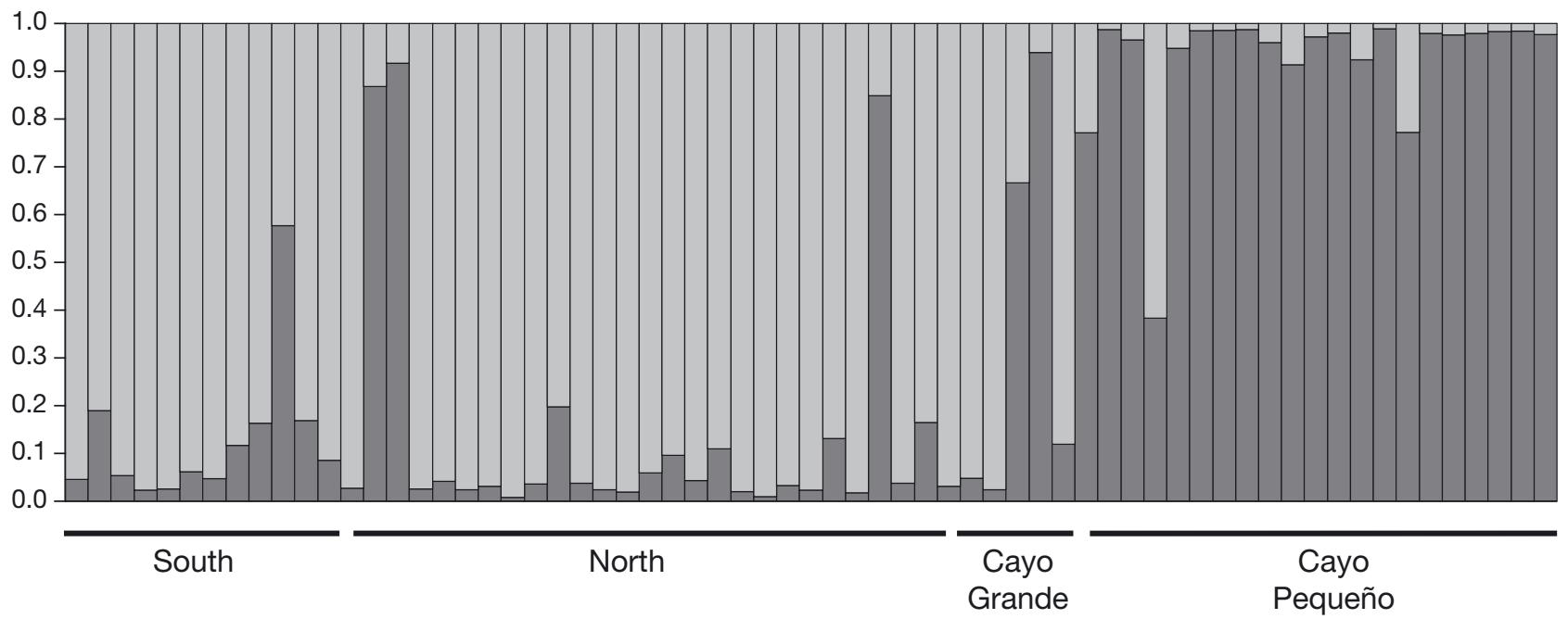

CTAC

C

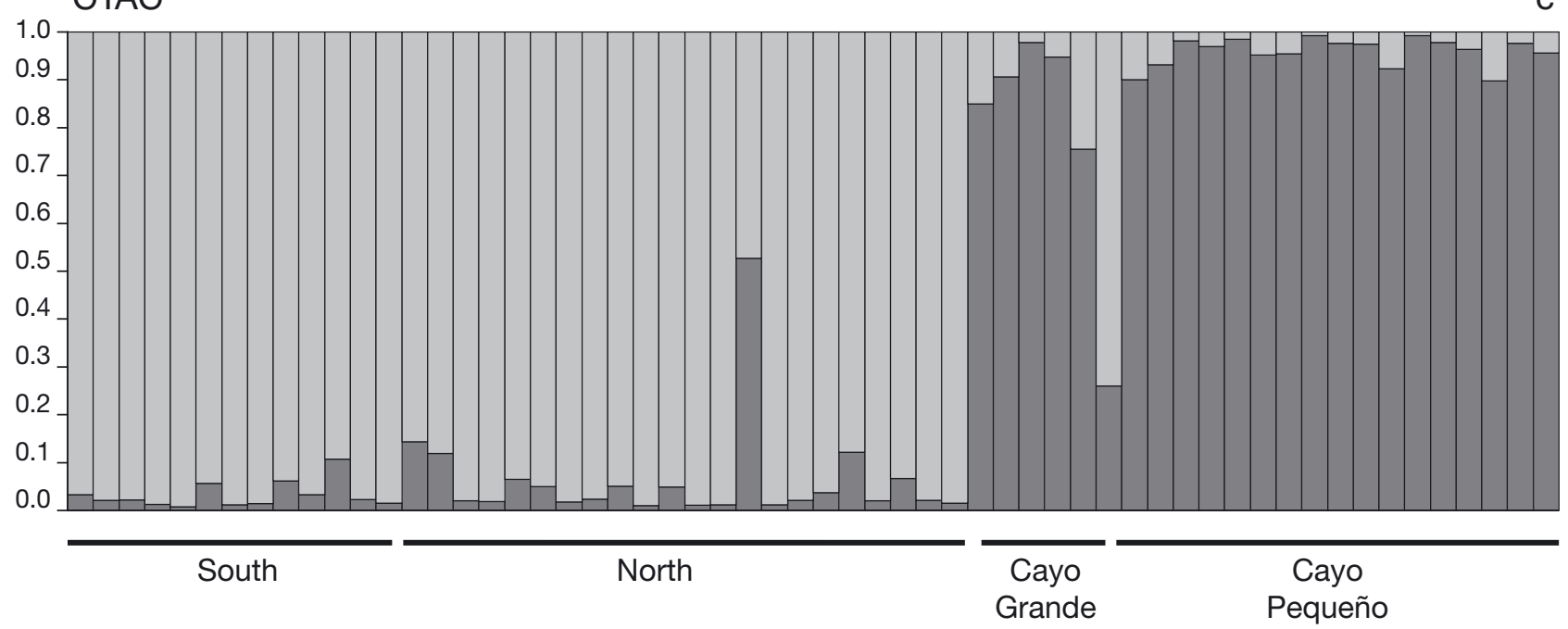

Fig. 3. STRUCTURE plots by primer, indicating the number of groups best supported. South (North): south (north) of the Rio Aguán see Fig. 1 for locations). Different shades of gray indicate different groups 


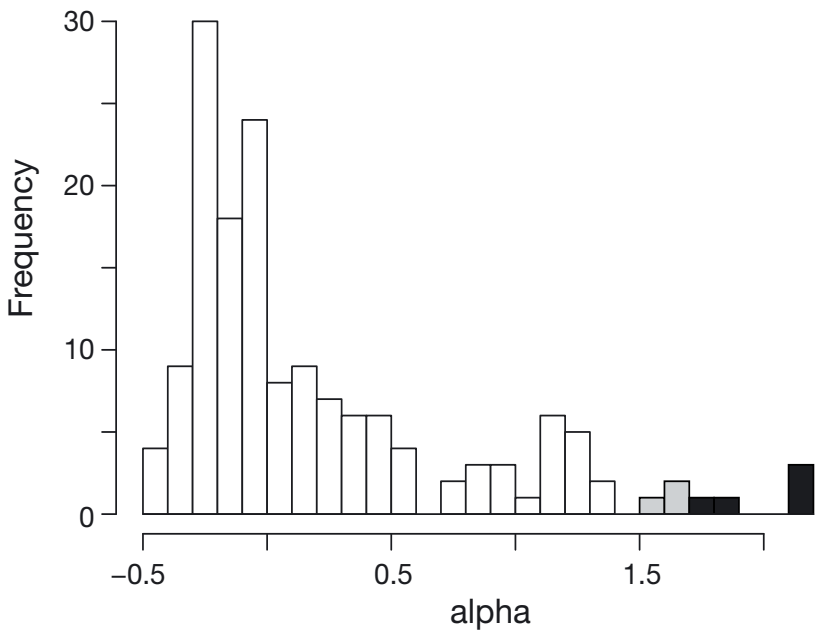

Fig. 4. Ctenosaura melanosterna. Frequency by which Foll \& Gaggiotti's (2008) $\alpha$ was observed, illustrating variation among amplified fragment length polymorphism (AFLP) markers in the degree of differentiation between mainland and island samples. Outliers detected by BayeScan (Foll \& Gaggiotti 2008) are shown in grey $\left(\operatorname{Pr}\left\{\alpha_{i} \neq 0\right.\right.$ I data $\left.\}>0.95\right)$ and black $\left(\operatorname{Pr}\left\{\alpha_{i} \neq 0\right.\right.$ | data $\left.\}>0.99\right)$

dividual iguana without the majority phenotype, and only a minority of variable bands were highly differentiated among groups. However, even when we removed the 8 loci that are seemingly associated with selection, we still saw support for the island-mainland separation $(K=2)$ in the STRUCTURE analysis.

\section{DISCUSSION}

Four concordant lines of data demonstrate that 2 separate ESUs should be considered within Ctenosaura melanosterna. The results from both the mtDNA and AFLP analyses show support for a split between the populations in the Valle de Aguán and Cayos Cochinos. Further, the AFLP data indicate possible adaptive differentiation between the 2 groups (Fig. 4), consistent with the strong contrast between the xeric, Acacia-dominated habitat of the Valle de Aguán and the more mesic oak forests of the Cayos Cochinos. Additional management units within these ESUs may be appropriate; some data support differentiation between the 2 islands or across the Rio Aguán, although these patterns need to be verified by additional data. What seems clear is that the relatively protected population of $C$. melanosterna on Cayo Pequeño is not representative of (or exchangeable with) the mainland form, and therefore, an irreplaceable element of biodiversity would be lost if the Valle de Aguán population were allowed to go extinct.

\section{Island and mainland ESUs}

The gene tree analysis of the mtDNA data clearly demonstrates a division between the island populations and the mainland populations, as none of the observed haplotypes was found in both general locations (Fig. 2). The AMOVA and SAMOVA analyses also showed support for this separation, with the addition of a separation between the mainland populations found on the south side of the Rio Aguán and those found to the north (Table 1). The AFLP data are concordant with the principal separation of Cayos Cochinos from the mainland; however, instead of showing support for an additional mainland separation, some of these data show support for separating Cayo Grande from Cayo Pequeño (Fig. 3, Table 3).

Understanding the structure, and thus defining the units and prioritizing those units, is vital to both a proactive and reactive conservation program (Brooks et al. 2006). One of the most commonly used and appropriate ways to classify groups of organisms for conservation is into ESUs, which are supported as 'species' or DPSs by the ESA. A variety of ways to define ESUs have been developed, and disagreement exists between these definitions (Waples 2006). Pennock \& Dimmick (1997) argued that this ambiguity is beneficial in allowing decisions to be made on a caseby-case basis, as to which variables are most important. As things stand, research is needed on a case-bycase basis to predict the consequences of alternative conservation strategies.

From sequencing a portion of the mitochondrial genome or scanning the nuclear genome, individuals from the mainland can be differentiated from those on Cayos Cochinos. Thus Moritz's (1994) criterion of significant differentiation at the nuclear level (Table 3) is met and the criterion of reciprocal monophyly (Fig. 2) is partially met with this dataset. In addition to the genetic data, by simply looking at the geography of the area one can deduce that the mainland and island populations are not only separated by an expanse of land but also by the Caribbean Sea; therefore, Waples' (1991) first criterion of reproductive isolation is also met with these data. However, to meet Waples' second criterion of distinct adaptations or evolutionary legacy and the similar criteria of many of the other definitions of an ESU (Ryder 1986, Dizon et al. 1992, Crandall et al. 2000), our attention must turn to evidence for adaptive variation or differential selection and concordance between additional lines of data.

The genomic heterogeneity in the degree of divergence inferred from BayeScan is consistent with adaptive differentiation between the mainland and island populations. The amount of variation exhibited by the AFLPs is low overall, implying recent isolation. How- 
ever, at least 5 alleles are strongly differentiated, likely as a result of local selective sweeps at linked loci. The Cayos Cochinos island habitat is dominated by evergreen oak forest, whereas cacti and Acacia plants dominate the Valle de Aguán mainland habitat. Although detailed dietary studies have not yet been conducted, it is clear that individuals in each population are foraging on extremely different plants, as there is little overlap in the flora between sites. Likewise, these different habitats afford different soil types and occur in areas of highly different weather patterns (S. A. Pasachnik pers. obs.). Therefore, the reproductive biology, such as nesting times, may also vary (Colli 1991, Gillis \& Ballinger 1991, Iverson et al. 1993, Jenkins et al. 2009).

Given the evidence of adaptive differentiation, Waples' (1991) criterion of preserving evolutionary legacy is met. There is also concordance between different lines of data including genetics, geography, and ecology, to support this conclusion. Thus the criteria of Dizon et al. (1992) are met and there is support for 2 ESUs. Further, following Crandall et al. (2000), we reject genetic and ecological exchangeability between the mainland and island populations. Ctenosaura melanosterna is therefore a case in which all lines of evidence, under all sets of criteria, support the same conclusion of 2 unique ESUs.

Although it might be interesting to know how long the 2 groups have been geographically separated, we have no means to reliably estimate a divergence time. The mtDNA gene tree is too shallow to support inference using a molecular clock approach (with so few substitutions between haplotype groups, inference of rates or times is highly imprecise), and coalescent approaches such as Isolation with Migration (IM) (Hey \& Nielsen 2004) require more independent loci for reliable inference, in addition to assumptions about population size and history that are probably unrealistic for endangered species. We can say that divergence has been sufficiently recent such that few nucleotide differences have accumulated and the mtDNA genealogy has not yet resolved into 2 clearly monophyletic groups.

\section{Demographic stability}

Using the simple summary statistics recommended by Finn et al. (2009), we did not reject the null hypothesis of demographic stability for any putative ESU or subpopulation. Caution should be taken when using this method of classifying both the stability of populations and in turn the long-term habitat stability, especially in the context of conservation and management. Although many of these statistics can be used with confidence to infer certain events, such as bottlenecks, failure to reject the null hypothesis should not be considered equivalent to accepting the conclusion of demographic stability. In other words, there may be biologically relevant events that have occurred but are statistically not significant, due to sample size or the power of the analysis (Fidler et al. 2006). Rigorous risk assessment might better be approached from a Bayesian perspective where a variety of priors are explored and their probability assessed, instead of simply rejecting or accepting a null hypothesis.

\section{Conservation implications}

The actions needed to protect these 2 ESUs are very different. The Cayos Cochinos populations are located within a National Monument and thus will continue to be afforded a certain degree of protection, although this varies from island to island as discussed above. In addition, the threats that the Cayos Cochinos populations face are greatly reduced in comparison to the mainland populations, as anthropogenic factors are not as prevalent. Continued protection of the Cayos Cochinos populations is expected. However, given the data presented herein, neglecting to protect the variation within the Valle de Aguán will greatly reduce the amount of biodiversity that is conserved.

Failure to take further action in the Valle de Aguán will result in the extirpation of these populations, leaving those on Cayos Cochinos as the only representatives of this species. Given that the Cayos Cochinos islands are small and in a hurricane zone, deciding to protect only these populations could result in the extinction of this species. In addition, it is likely that Ctenosaura melanosterna plays an integral role in the functioning of the unique dry tropical forest that occurs in the Valle de Aguán, just as its sister species C. palearis (Pasachnik et al. 2010) plays in the ecologically similar Valle de Motagua (Coti \& Ariano 2008). Thus the extirpation of C. melanosterna could have a negative impact on the entire Valle de Aguán ecosystem.

Management strategies such as translocations, or the creation of rescue populations, and captive breeding and release programs have been discussed for this species. Failure to preserve the 2 distinct units identified herein might result in the elimination of differential adaptations to their respective environments. The relocation or release of individuals into areas of the 'other' ESU and the subsequent interbreeding may result in the deleterious effects of outbreeding depression in the following generations (e.g. Sunnucks \& Tait 2001), and, in turn, the possible extinction of the species. Further, because the exact substructure within 
each of the units is not yet understood, breeding and translocation programs should respect the secondary subdivisions (separation of the islands and the north and south side of the Aguán River), until there are ample data to do otherwise. Lastly, those individuals that are currently in ex situ breeding programs, and for which the origin is unknown, should not be released into the wild until their origin can be determined, because of the potential harm outbreeding depression could cause to the species as a whole.

Acknowledgements. This study would not have been possible without the help of R. F. Steiner, E. A. Pineda, C. R. Carias, J. Corneil, C. E. Montgomery, and a multitude of local residents and guides, many thoughtful discussions with J. Iverson, J. Fordyce, and S. Horn, The Bay Island Foundation, and the Iguana Research and Breeding Station and its helpful staff, the Cayos Cochinos Foundation, the many offices of ICF (formerly AFE-COHDEFOR), and grants to S.A.P. from Sigma Xi and the International Iguana Foundation, and the Department of Ecology and Evolutionary Biology of the University of Tennessee, Knoxville. Thanks to Daniel Ariano for aiding in the construction of the distribution map. All procedures were approved by the University of Tennessee, Knoxville, Institutional Animal Care and Use Committee.

\section{LITERATURE CITED}

Avise JC (2005) Phylogenetic units and currencies above and below the species level. In: Purvis A, Gittleman JL, Brooks $\mathrm{T}$ (eds) Phylogeny and conservation. Cambridge University Press, New York, NY, p 77-100

Bermingham E, Coates A, Cruz Diaz G, Emmons L and others (1998) Geology and terrestrial flora and fauna of Cayos Cochinos, Honduras. Rev Biol Trop 46 (Suppl 4):15-37

Brooks TM, Mittermeier RA, da Fonseca GAB, Gerlach J and others (2006) Global biodiversity conservation priorities. Science 313:58-61

Brummitt N, Lughadha EN (2003) Biodiversity: Where's hot and where's not. Conserv Biol 17:1442-1448

Buckley LJ, Axtell RW (1997) Evidence for specific status of the Honduran lizards formally referred to as Ctenosaura palearis (Reptilia: Squamata: Iguanidae). Copeia 1997: 138-150

> Caro T, Engilis A, Fitzherbert E, Gardner T (2004) Preliminary assessment of the flagship species concept at a small scale. Anim Conserv 7:63-70

Colli GR (1991) Reproductive ecology of Ameiva ameiva (Sauia, Teiidae) in the Cerrado of Central Brazil. Copeia 1991:1002-1012

Coti P, Ariano D (2008) Ecology and traditional use of the Guatemalan black iguana (Ctenosaura palearis) in the dry forests of the Motagua Valley, Guatemala. Iguana 3: 142-149

Crandall KA, Bininda-Edmonds ORP, Mace GM, Wayne RK (2000) Considering evolutionary processes in conservation biology: an alternative to 'evolutionarily significant units'. Trends Ecol Evol 15:290-295

> Davis GE (2005) Science and society: marine reserve design for the California Channel Islands. Conserv Biol 19: 1745-1751

> Dizon AE, Lockyer C, Perrin WF, Demaster DP, Sisson J (1992) Rethinking the stock concept-a phylogeographic approach. Conserv Biol 6:24-36
Dupanloup I, Schneider S, Excoffier L (2002) A simulated annealing approach to define the genetic structure of populations. Mol Ecol 11:2571-2581

Echternacht AC (1968) Distributional and ecological notes on some reptiles from northern Honduras. Herpetologica 24: 151-158

Evanno G, Regnaut S, Goudet J (2005) Detecting the number of clusters of individuals using the software STRUCTURE: a simulation study. Mol Ecol 14:2611-2620

Ewens WJ (1972) Sampling theory of selective neutral alleles. Theor Popul Biol 3:87-112

> Excoffier L, Smouse PE, Quattro JM (1992) Analysis of molecular variance inferred from metric distances among DNA haplotypes: application to human mitochondrial DNA restriction data. Genetics 131:479-491

> Excoffier L, Laval G, Schneider S (2005) Arlequin ver. 3.0: an integrated software package for population genetics data analysis. Evol Bioinform Online 1:47-50

Excoffier L, Hofer T, Foll M (2009) Detecting loci under selection in a hierarchically structured population. Heredity 103:285-298

Falush D, Stephens M, Pritchard JK (2007) Inference of population structure using multilocus genotype data: dominant markers and null alleles. Mol Ecol Notes 7:574-578

- Felsenstein J (1985) Confidence limits on phylogenies: an approach using the bootstrap. Evolution 39:783-791

> Fidler F, Burgman MA, Cumming G, Buttrose R, Thomason N (2006) Impact of criticism of null-hypothesis significance testing on statistical reporting practices in conservation biology. Conserv Biol 20:1539-1544

> Finn DS, Bogan MT, Lytle DA (2009) Demographic stability metrics for conservation prioritization of isolated populations. Conserv Biol 23:1185-1194

> Fitzpatrick BM (2009) Power and sample size for nested analysis of molecular variance. Mol Ecol 18:3961-3966

Fitzpatrick BM, Placyk JS, Niemiller ML, Casper GS, Burghardt GM (2008) Distinctiveness in the face of gene flow: hybridization between specialist and generalist gartersnakes. Mol Ecol 17:4107-4117

Foll M, Gaggiotti O (2008) A genome-scan method to identify selected loci appropriate for both dominant and codominant markers: a Bayesian perspective. Genetics 180: 977-993

Fu YX (1997) Statistical tests of neutrality of mutations against population growth, hitchhiking and background selection. Genetics 147:915-925

- Fu YX, Li WH (1993) Statistical tests of neutrality of mutations. Genetics 133:693-709

Gillis R, Ballinger RE (1991) Reproductive ecology of redchinned lizards (Sceloporus undulatus erythrocheilus) in southcentral Colorado: comparisons with other populations of a wide-ranging species. Oecologia 89:236-243

Gutsche A (2005) Distribution and habitat utilization of Ctenosaura bakeri on Utila. Iguana 12:143-151

Harpending H (1994) Signature of ancient population growth in a low-resolution mitochondrial DNA mismatch distribution. Hum Biol 66:591-600

Hey J, Nielsen R (2004) Multilocus methods for estimating population sizes, migration rates and divergence time, with applications to the divergence of Drosophila pseudoobscura and D. persimilis. Genetics 167:747-760

Hobbs RJ, Mooney HA (1998) Broadening the extinction debate: population deletions and additions in California and Western Australia. Conserv Biol 12:271-283

Hoekstra JM, Boucher TM, Ricketts TH, Roberts C (2005) Confronting a biome crisis: global disparities of habitat loss and protection. Ecol Lett 8:23-29 
Hughes JB, Daily GC, Ehrlich PR (1997) Population diversity: its extent and extinction. Science 278:689-692

Iverson JB, Balgooyen CP, Byrd KK, Lyddan KK (1993) Latitudinal variation in egg and clutch size in turtles. Can J Zool 71:2448-2461

Jenkins CL, Peterson CR, Doering SC, Cobb VA (2009) Microgeographical variation in reproductive characteristics among western rattlesnake (Crotalus oreganus) populations. Copeia 2009:774-780

Köhler G (2003) The reptiles of Central America. Herpeton, Verlag Elke Köhler, Offenbach

Longmire JL, Gee GF, Hardekopf CL, Mark GA (1992) Establishing paternity in whooping cranes (Grus americana) by DNA analysis. Auk 109:522-529

Luck GW, Daily GC, Ehrlich PR (2003) Population diversity and ecosystem services. Trends Ecol Evol 18:331-336

Mace GM (2000) It's time to work together and stop duplicating conservation efforts. Nature 405:393

Maddison DR, Maddison WP (2005) MacClade 4 release version 4.07 for OSX. Sinauer Associates, Sunderland, MA

McCranie JR, Wilson LD, Kohler G (2005) Amphibians and reptiles of the Bay Islands and Cayos Cochinos, Honduras. Bibliomania!, Salt Lake City, UT

Misawa K, Tajima F (1997) Estimation of the amount of DNA polymorphism when the neutral mutation rate varies among sites. Genetics 147:1959-1964

Mittermeier RA, da Fonseca GAB, Brooks T, Pilgrim J, Rodrigues A, Myers N (2003) Hotspots and coldspots. Am Sci 91:384

Moritz C (1994) Defining 'evolutionarily significant units' for conservation. Trends Ecol Evol 9:373-375

Moritz C, Cicero C (2004) DNA barcoding: promise and pitfalls. PLoS Biol 2:e354

> Myers N, Knoll AH (2001) The biotic crisis and the future of evolution. Proc Natl Acad Sci USA 98:5389-5392

Myers N, Mittermeier RA, Mittermeier CG, da Fonseca GAB, Kent J (2000) Biodiversity hotspots for conservation priorities. Nature 403:853-858

Pasachnik SA, Fitzpatrick BM, Near TJ, Echternacht AC (2009) Gene flow between an endangered endemic iguana, and its wide spread relative, on the island of Utila, Honduras: When is hybridization a threat? Conserv Genet 10:1247-1254

Pasachnik SA, Echternacht AC, Fitzpatrick BM (2010) Gene trees, species and species trees in the Ctenosaura melanosterna clade. Conserv Genet 11:1767-1781

Pennock DS, Dimmick WW (1997) Critique of the evolutionarily significant unit as a definition for 'distinct population segments' under the U.S. Endangered Species Act. Conserv Biol 11:611-619

Pimm SL, Russell GJ, Gittleman JL, Brooks TM (1995) Hotspots and the conservation of evolutionary history. Science 269:347-350

Posada D, Crandall KA (1998) Modeltest: testing the model of DNA substitution. Bioinformatics 14:817-818

Pritchard JK, Stephen M, Donnelly P (2000) Inference of pop-

Editorial responsibility: Steven Rossiter,

London, UK ulation structure using multilocus genotype data. Genetics 155:945-959

Ramos-Onsins SE, Rozas J (2002) Statistical properties of new neutrality tests against population growth. Mol Biol Evol 19:2092-2100

Rogers AR, Fraley AE, Bamshad MJ, Watkins WS, Jorde LB (1996) Mitochondrial mismatch analysis is insensitive to the mutational process. Mol Biol Evol 13:895-902

Ronquist F, Huelsenbeck JP (2003) MRBAYES 3: Bayesian phylogenetics inference under mixed models. Bioinformatics 19:1572-1574

Rozas J, Sanchez-DelBarrio JC, Messeguer X, Rozas R (2003) DnaSP, DNA polymorphism analyses by the coalescent and other methods. Bioinformatics 19:2496-2497

Ryder OA (1986) Species conservation and systematics: the dilemma of subspecies. Trends Ecol Evol 1:9-10

Sanderson EW, Jaiteh M, Levy MA, Redford KH, Wannebo AV, Woolmer G (2002) The human footprint and the last of the wild. Bioscience 52:891-904

> Stewart RR, Possingham HP (2005) Efficiency, costs and trade-offs in marine reserve system design. Environ Model Assess 10:203-213

Sunnucks P, Tait N (2001) Velvet worms: tales of the unexpected. Nat Aust 27:60-69

Swofford DL (2002) PAUP*. Phylogenetic analysis using parsimony ( ${ }^{*}$ and other methods). Version 4.0. Sinauer Associates, Sunderland, MA

Tajima F (1997) The amount of DNA polymorphism maintained in a finite population when neutral mutation rate varies among sites. Genetics 143:1457-1465

Toscano MA, Macintyre IG (2003) Corrected western Atlantic sea-level curve for the last 11,000 years based on calibrated ${ }^{14} \mathrm{C}$ dates from Acropora palmata framework and intertidal mangrove peat. Coral Reefs 22:257-270

Vekemans X (2002) AFLP-SURV version 1.0. Laboratoire de Génétique et Ecologie Végétale, Université Libre de Bruxelles

> Vos P, Hogers M, Bleeker M, Reijans M and others (1995) AFLP: a new technique for DNA fingerprinting. Nucleic Acids Res 23:4407-4414

- Wake DB, Vredenburg VT (2008) Are we in the midst of the sixth mass extinction? A view from the world of amphibians. Proc Natl Acad Sci USA 105:11466-11473

Waples RS (1991) Pacific salmon, Oncorhynchus spp., and the definition of 'species' under the Endangered Species Act. Mar Fish Rev 53:11-22

Waples RS (2006) Distinct population segments. In: Scott JM, Goble DD, Davis FW (eds) The Endangered Species Act at thirty: conserving biodiversity in human dominated landscapes. Island Press, Washington, DC, p 127-149

Wilson LD, Cruz Diaz GA (1993) The herpetofauna of the Cayos Cochinos, Honduras. Herpetol Nat Hist 1:13-23

- Wilson LD, McCranie JR (2004) The conservation status of the herpetofauna of Honduras. Amphib Reptile Conserv 3:6-33

> Woinarski JCZ, Fisher A (1999) The Australian Endangered Species Act 1992. Conserv Biol 13:959-962

Submitted: August 26, 2010; Accepted: February 24, 2011

Proofs received from author(s): May 6, 2011 